\title{
Interactive scaling: A demonstration
}

\author{
REX S. GREEN \\ University of California, San Francisco Medical Center, San Francisco, California 94143
}

Described is one of the new techniques that interactive scaling algorithms make possible.

Numerous applications of multidimensional scaling (MDS) models require sets of stimuli larger than 20. This requirement has spurred the development of several means of fitting the complete MDS model with far fewer than $\mathrm{N}(\mathrm{N}-1) / 2$ stimulus pairings for $\mathrm{N}$ stimuli. For example, 20 stimuli require that 190 such pairings be judged; 40 require 780 .

A series of algorithms has been programmed for on-line computing applications that present a small subset of all the stimulus pairings, of ten about one-third. INTERSCAL (Cliff, Girard, Green, Kehoe, \& Doherty, $1977)$ is the most current version available. It was tested by Girard and Cliff (1976), and improvements were suggested by Green and Bentler (1979). Subsequently, I have been developing a different algorithm that makes better use of the changes recommended by Green and Bentler (1979). While some Monte Carlo tests have been run on the new algorithm (Green, Note 1), several further changes are being made. A report of these developments is currently in preparation.

In collaboration with Lydia Temoshok, a clinical psychologist at the Langley Porter Institute and the Department of Psychiatry, University of California San Francisco Medical Center, I have been applying the new interactive scaling algorithm to problems in psychotherapy assessment. One such application is the topic of this paper.

Before describing the clinical application, here is a brief review of the operation of INTERSCAL, for those readers who are less familiar with the interactive scaling approach to conducting MDS studies. INTERSCAL starts by selecting the first eight stimuli on a list, which the user supplies, to form a "focus." It collects judgments for all distinct stimulus pairs within this and each subsequent focus. Then, it analyzes each set of focus judgments to identify the best "basis" set of stimuli. A basis set defines the dimensionality of the space and consists of $r+1$ stimuli for $r$-dimensional spaces. The basis set of stimuli should "frame" all or nearly all of the stimulus points in the spatial representation, much as

Since presenting this paper at the conference in Phoenix, Arizona, on November 7, 1979, the author has moved. Requests for reprints should be sent to Rex S. Green, Eastern Pennsylvania Psychiatric Institute, Henry Avenue and Abbottsford Road, Philadelphia, Pennsylvania 19129. This investigation was supported in part by a research and instruction award (IUC 247622-1990) from the University of California. a frame surrounds its picture. The best basis in the first focus is carried forward to succeeding foci until, after the last set of focus judgments is analyzed, the final basis is selected. The final basis or frame stimuli are compared to all remaining stimuli. Lastly, INTERSCAL correlates those judgments that were collected a second time from the same judge with the original judgments. This correlational estimate of the judge's reliability is used to decide how many more frame stimuli to select and compare with all other stimuli. Although the new algorithm performs somewhat differently from INTERSCAL, the results are notably better (Green, Note 1).

\section{METHOD}

One key element in performing MDS studies is the selection of a homogeneous set of stimuli for which the pairwise similarities can be meaningfully judged. The following application focuses on words and phrases extracted from a letter written to a grandson. This application illustrates how a therapist and patient might "share" their perceptions of some important event in the patient's life (i.e., receiving a letter). The letter was written just prior to the grandmother's death; it consisted of $41 \mathrm{key}$ phrases or words. Both the therapist and grandson interacted with the new algorithm to provide a small subset of all pairwise judgments of dissimilarity among these 41 stimuli. Only the therapist's perceptions will be reported.

\section{RESULTS}

Table 1 contains the stimulus names, grouped by a clustering procedure (Veldman, 1967), and the spatial coordinates for the two-dimensional solution. However, the richness of the structure is best viewed using a point plot with shortened stimulus names. Of the 820 distinct stimulus pairings, the therapist judged only 184 , or $23 \%$. The correlation of the 184 judgments with their corresponding spatial distances was .77. This was slightly lower than the repeated-judgments correlation for 38 pairs of .81 . Presumably, the complexity of these stimuli lowered the levels of fit and consistency of judgment. Because the fit correlation was lower than the repeated-judgments correlation, the solution might have been improved by adding a few more stimuli to the frame to improve the level of fit. However, these results would not improve notably, even though over $75 \%$ of all judgments were collected, given the relatively low repeated-judgments correlation.

The therapist's interpretation of the structure was as follows. The first dimension distinguished cheeriness, 
Table 1

Clusters and Dimension Loadings of the Letter Stimuli

\begin{tabular}{|c|c|c|c|}
\hline \multirow{2}{*}{$\begin{array}{c}\text { Clus- } \\
\text { ter }\end{array}$} & \multirow[b]{2}{*}{ Stimulus } & \multicolumn{2}{|c|}{ Dimension } \\
\hline & & 1 & 2 \\
\hline A & Decorative Calendar & -4.47 & 2.21 \\
\hline B & Erotic Love & -2.37 & -3.58 \\
\hline $\mathbf{B}$ & Go Out and Play & -1.39 & -2.00 \\
\hline $\mathrm{B}$ & Cheer & -2.98 & -2.82 \\
\hline $\mathrm{B}$ & She'd See Me Next Summer & -2.98 & -2.37 \\
\hline B & A Happier Time & -2.98 & -2.37 \\
\hline B & Ghiradelli Square & -3.28 & -2.18 \\
\hline $\mathrm{B}$ & Reunion & -2.54 & -3.06 \\
\hline $\mathrm{C}$ & The Atlantic Coast & 1.44 & 2.30 \\
\hline $\mathrm{C}$ & Death, Land of the Dead & .50 & 4.41 \\
\hline $\mathrm{C}$ & I Hadn't Seen X for Ages & 1.20 & 1.86 \\
\hline $\mathrm{C}$ & Weather Reports & 1.19 & 4.34 \\
\hline $\mathrm{C}$ & The Saddest Christmas of my Life & .05 & 4.60 \\
\hline $\mathrm{C}$ & Blizzard Howl & 1.68 & 2.41 \\
\hline $\mathrm{C}$ & Parting & .67 & 2.82 \\
\hline $\mathrm{C}$ & When the No School Bell Rang & 1.60 & 3.26 \\
\hline $\mathrm{C}$ & The East & .30 & 2.55 \\
\hline $\mathrm{C}$ & Cremation & 1.74 & 4.34 \\
\hline $\mathrm{C}$ & Impending Death & .73 & 4.78 \\
\hline $\mathrm{C}$ & Her Time was Short & .18 & 3.51 \\
\hline $\mathrm{C}$ & Her next Stop, New Haven & .74 & 2.82 \\
\hline $\mathrm{D}$ & Blizzards & 4.51 & 2.95 \\
\hline $\mathrm{D}$ & Buried in Snow & 4.59 & 1.83 \\
\hline D & The Mysterious East & 4.46 & -1.52 \\
\hline $\mathrm{E}$ & Reminiscing & -.66 & 1.97 \\
\hline $\mathrm{E}$ & Seeing Them Before Me & .24 & 1.53 \\
\hline $\mathrm{E}$ & It was Good to See Her & .62 & -1.02 \\
\hline $\mathbf{E}$ & Madeira Handkerchief & -.37 & .43 \\
\hline $\mathrm{E}$ & Whether or Not & 1.37 & .00 \\
\hline $\mathbf{E}$ & Sara Back & .50 & -.57 \\
\hline $\mathbf{E}$ & Moot Question & .56 & -.57 \\
\hline $\mathrm{E}$ & Anniversary & -.70 & .00 \\
\hline $\mathrm{E}$ & Lunch & .57 & .00 \\
\hline $\mathrm{E}$ & Christmas of my Life & .88 & -.13 \\
\hline $\mathrm{E}$ & When Hester and I were Together & .30 & .70 \\
\hline $\mathrm{E}$ & Day Before Christmas & .63 & .00 \\
\hline $\mathbf{E}$ & Red Camellia Card & -.74 & .57 \\
\hline $\mathbf{E}$ & Welcome back to the USA & .51 & .00 \\
\hline E & U.S.A. & .15 & -.32 \\
\hline $\mathbf{E}$ & The Magic Pan & .69 & -1.02 \\
\hline $\mathbf{F}$ & Life, Land of the Living & .66 & -5.17 \\
\hline
\end{tabular}

surface-level issues, and warmth from threatening experiences, deep-level issues, and cold. The second dimension isolated life and the living from a host of phrases related to death. A third dimension, linearly related to the first two, contrasted happy, neutral, and sad meetings that the grandmother had experienced over the years. This dimension extended from Cluster B through Cluster C.

\section{DISCUSSION}

Clearly, the therapist's understanding of the grand- mother's letter was interpretable. The subject of death was the focus of the letter. Perhaps this letter was her way of making part of the transition from life to death. Reminiscing was mentioned in the letter; as a stimulus, it is located near the middle of this space. Does this suggest the central importance of reminiscing in preparation for death? What was the grandson's role in this process? Do his perceptions of the stimuli provide some clues? Should his understanding of the letter become more like the therapist's, or vice versa? These questions are raised to illustrate how the therapist might make use of these results. Naturally, the nature of the therapy and the therapist-patient relationship set the context for identifying and handling the salient issues.

Returning to some technical issues, some of these 41 stimulus locations are poorly defined (i.e., very wobbly) due to the poor fit and low consistency of judgment. Nonetheless, the therapist was quite clear about these interpretations and their relevance to the grandson's interpretation of this letter. Occasionally, it may be necessary to allow the judge, in this case the therapist, to shift some points around in the space to clarify the interpretations.

The computing configuration for this study consisted of an IBM 370 main frame linked via the IBM conversational monitoring system software to a Perkin-Elmer CRT. The turnaround time for entering these stimuli, judging the selected pairs, and interpreting a printed copy of the results could be as little as $2.5-3 \mathrm{~h}$. The run costs were under $\$ 10$.

Thus, it seems feasible that this approach to examining crucial events in a person/patient's life could be usefully employed by clinicians who have access to on-line computing services.

\section{REFERENCE NOTE}

1. Green, R. S. Evaluating a new algorithm for interactive MDS. Paper presented at the meeting of the Psychometric Society, University of North Carolina, Chapel Hill, North Carolina, June 1977.

\section{REFERENCES}

Cliff, N., Girard, R., Green, R. S., Kehoe, J. F., \& Doherty, L. M. INTERSCAL: A TSO FORTRAN IV program for subject computer interactive multidimensional scaling. Educational and Psychological Measurement, 1977, 37, 185-188.

Girard, R., \& ClifF, N. A Monte Carlo evaluation of interactive multidimensional scaling. Psychometrika, 1976, 41, 43-64.

Green, R. S., \& Bentler, P. M. Improving the efficiency and effectiveness of interactively selected MDS data designs. Psychometrika, 1979, 44, 115-119.

VELDMAN, D. J. FORTRAN programming for the behavioral sciences. New York: Holt, Rinehart, \& Winston, 1967. 